\title{
Use of Factor Scores for Predicting Body Weight from Some Morphometric Measurements of Two Fish Species in Nigeria
}

\author{
Abdulmojeed Yakubu ${ }^{1}$, Samuel A. Okunsebor ${ }^{2}$, Alex A. Kigbu ${ }^{2}$, Akeem O. Sotolu ${ }^{2} \&$ Terzungwe D. Imgbian ${ }^{2}$ \\ ${ }^{1}$ Department of Animal Science, Faculty of Agriculture, Nasarawa State University, Nigeria \\ ${ }^{2}$ Department of Forestry, Wildlife and Fisheries, Faculty of Agriculture, Nasarawa State University, Nigeria \\ Correspondence: Abdulmojeed Yakubu, Department of Animal Science, Faculty of Agriculture, Nasarawa State \\ University, Keffi, Shabu-Lafia Campus, P.M.B. 135, Lafia 950101, Nigeria. E-mail: abdul_mojeedy@yahoo.com
}

Received: March 23, 2010 Accepted: April 7, 2010 Online Published: June 29, 2012

doi:10.5539/jas.v4n8p60 URL: http://dx.doi.org/10.5539/jas.v4n8p60

\begin{abstract}
The interpretation of several traits contributing to body weight prediction is difficult due to the high degree of correlation among them. Based on this, we examined the relationships between body weight and six morphometric traits (standard length, total length, head length, body depth, dorsal length and caudal length) of two fish species, Oreochromis niloticus and Lates niloticus sampled in Doma Dam, Nasarawa State, Nigeria. The statistical approach adopted was the multivariate principal component factor analysis technique. Two principal components were obtained in Oreochromis niloticus while three components were extracted for Lates niloticus. Their respective factor scores fitted separately in a multiple linear regression model as explanatory variables accounted for $76.6 \%$ and $84.5 \%$ of the variation in the body weight of the two fish species.
\end{abstract}

Keywords: fishery resource, biometric trait, multivariate analysis, multiple regression

\section{Introduction}

Size is generally more important than age in fish, mainly because several ecological and physiological factors are more size-dependent than age-dependent (Kalayci et al., 2007). Oreochromis niloticus and Lates niloticus are among the most known members of the tropical and subtropical freshwater fishes. The former is recommended by the FAO as a culture fish species because of its importance in aquaculture and its capability in contributing to the increased production of animal protein in the world. Experiments related to animal science are often conducted to develop a model to represent and explain the relationships between variables. Published reports on the relationship between body weight and morphometric measurements of fish are important for the studies on biology, population dynamics and management of species (Ismen, 2002; Mendes et al., 2004; Fafioye \& Oluajo, 2005).

Multiple regression analysis has been used to interpret the complex relationships among body weight and some body measurements. However, its interpretation may be misleading where there exists multicollinearity among the predictor variables. To address this limitation, multivariate factor analysis is more suitable as a statistical method for reducing a complex system of correlations into one of smaller dimensions through the extraction of a few unobservable latent variables, called factors (Tabachnick \& Fidell, 2001). Factor scores can be derived from such multivariate analysis which could be nearly uncorrelated or orthogonal. Such factor scores could therefore be used for prediction, thereby solving the problem of multicollinearity.

In Nigeria, sub-saharan Africa, information on the use of multivariate statistical approach to elucidate the structural relationships among morphometric traits of fish is lacking. Therefore, the present investigation aimed at estimating the body weight of two fresh water fish species (Oreochromis niloticus and Lates niloticus) from their body measurements using principal component factor analysis.

\section{Materials and Methods}

Two hundred and fifty two mature fish samples comprising 153 Oreochromis niloticus and 99 Lates niloticus of both sexes were harvested in Doma Dam, Nasarawa State, Nigeria from May to June, 2009. The minimum and maximum atmospheric temperatures during the study period were 23.7 and $31^{\circ} \mathrm{C}$ respectively. The water (Dam) average temperature and $\mathrm{p}^{\mathrm{H}}$ were $28^{\circ} \mathrm{C}$ and 7.5 respectively. Seven morphological measurements were made on each specimen following standard anatomical reference points (Omoniyi \& Agbon, 2004, Alp \& Kara, 2007). The body traits measured were body weight (BW), standard length (SL), total length (TL), head length (HL), 
body depth (BD), dorsal fin length (DL) and caudal fin length (CL). The weight measurement was done using a digital scale while the length measurements were carried out using digital caliper.

Data on the morphometric measurements (body weight, standard length, total length, head length, body depth, dorsal fin length and caudal fin length) of the two fish species were transformed to common logarithms in order to increase linearity and multivariate normality (Pinheiro et al., 2005). Log transformed data were then analyzed using univariate [analysis of variance (ANOVA), with means separated using the two-tailed, two-sample t-test] and multivariate statistical methods. The multivariate technique involved the use of principal components. Principal components (PC) are a weighted linear combination of correlated variables, explaining a maximal amount of variance of the variables (Truxillo, 2003) thereby aiding in data reduction. In the PC analysis, cumulative proportion of variance criterion was employed in determining the number of components to extract. The varimax criterion of the orthogonal rotation method was employed in the rotation of the factor matrix to enhance the interpretability of the factor analysis. Factor scores derived from the PC analysis were considered as independent variables for predicting the body weight of fish using the linear multiple regression model. All data were analyzed using the SPSS (2001) statistical package.

\section{Results and Discussion}

The basic descriptive statistics [mean, standard deviation, standard error and coefficient of variation (CV)] of body weight and body measurements of Oreochromis niloticus and Lates niloticus are presented in Table 1. The $\mathrm{CV}$ indicates the level of variation of the traits which could serve as a basis for improvement.

Table 1. Descriptive statistics for body weight and morphometric characters of Oreochromis niloticus and Lates niloticus

\begin{tabular}{lllllllll}
\hline \multirow{2}{*}{ Traits } & \multicolumn{3}{c}{ Oreochromis niloticus } & & \multicolumn{3}{c}{ Lates niloticus } \\
\cline { 2 - 4 } \cline { 6 - 8 } & Mean \pm SE & SD & CV (\%) & & Mean \pm SE & SD & CV (\%) \\
\hline BW (g) & $6.14 \pm 0.03$ & 0.34 & 5.54 & & $6.44 \pm 0.02$ & 0.19 & 2.95 \\
SL (cm) & $2.95 \pm 0.01$ & 0.17 & 5.76 & & $3.30 \pm 0.01$ & 0.11 & 3.33 \\
TL (cm) & $3.16 \pm 0.01$ & 0.14 & 4.43 & & $3.45 \pm 0.01$ & 0.09 & 2.61 \\
HL (cm) & $1.94 \pm 0.01$ & 0.18 & 9.28 & & $2.16 \pm 0.02$ & 0.18 & 8.33 \\
BD (cm) & $2.22 \pm 0.01$ & 0.16 & 7.21 & & $2.39 \pm 0.02$ & 0.18 & 7.53 \\
DL (cm) & $2.53 \pm 0.02$ & 0.22 & 8.70 & & $2.48 \pm 0.02$ & 0.23 & 9.27 \\
CL (cm) & $1.75 \pm 0.02$ & 0.26 & 14.86 & & $2.08 \pm 0.22$ & 0.22 & 10.58 \\
\hline
\end{tabular}

SE: Standard error, SD: Standard deviation, CV: Coefficient of variation. $\mathrm{BW}=$ body weight, $\mathrm{SL}=$ standard length, $\mathrm{TL}=$ total length, $\mathrm{HL}=$ head length, $\mathrm{BD}=$ body depth, $\mathrm{DL}=$ dorsal fin length and $\mathrm{CL}=$ caudal fin length.

Table 2. Phenotypic correlations among body weight and body measurements of Oreochromis niloticus and Lates niloticus

\begin{tabular}{llllllll}
\hline Traits & BW & SL & TL & HL & BD & DL & CL \\
\hline BW & & 0.79 & 0.59 & 0.83 & 0.83 & 0.84 & 0.70 \\
SL & 0.82 & & 0.88 & 0.80 & 0.80 & 0.80 & 0.66 \\
TL & 0.85 & 0.98 & & 0.62 & 0.64 & 0.62 & 0.51 \\
HL & 0.71 & 0.59 & 0.92 & & 0.85 & 0.78 & 0.70 \\
BD & 0.76 & 0.63 & 0.79 & 0.80 & & 0.82 & 0.75 \\
DL & 0.82 & 0.71 & 0.66 & 0.70 & 0.63 & & 0.80 \\
CL & 0.67 & 0.60 & 0.62 & 0.64 & 0.55 & 0.71 & \\
\hline
\end{tabular}

*Significant at $\mathrm{P}<0.01$ for all correlation coefficients.

Upper matrix: Oreochromis niloticus

Lower matrix: Lates niloticus

$\mathrm{BW}=$ body weight, $\mathrm{SL}=$ standard length, $\mathrm{TL}=$ total length, $\mathrm{HL}=$ head length, $\mathrm{BD}=$ body depth, $\mathrm{DL}=$ dorsal fin length and $\mathrm{CL}=$ caudal fin length. 
The phenotypic correlations among the various body parameters of the two fish species are presented in Table 2 . Body weight was highly and positively correlated with all the morphological characters. However, among the linear type traits, the highest correlation (r) was observed between standard length and total length in both fish species ( $\mathrm{r}=0.88$ and 0.98 for Oreochromis niloticus and Lates niloticus respectively). The lowest correlation was between total length and caudal fin length in Oreochromis niloticus $(\mathrm{r}=0.51)$ and between caudal length and body depth in Lates niloticus $(\mathrm{r}=0.55)$. Positive association between body weight and morphometric attributes has earlier been reported (Wang et al. 2008). Similarly, Cherif et al. (2008) reported high degree of positive correlation between total length and total weight of the 11 fish species investigated. High positive relationships among traits suggest that an increase in one could lead to a corresponding increase in the other trait. As a result of such high correlations, it is possible to predict growth of the whole body from parts thereof.

Table 3. Explained variation associated with rotated factors along with factor loadings and communalities of morphological traits of Oreochromis niloticus and Lates niloticus

\begin{tabular}{|c|c|c|c|c|c|c|c|}
\hline \multirow[t]{2}{*}{ Trait } & \multicolumn{3}{|c|}{ Oreochromis niloticus } & \multicolumn{4}{|c|}{ Lates niloticus } \\
\hline & $\mathrm{PC} 1$ & PC2 & Communality & $\mathrm{PC} 1$ & PC2 & PC3 & Communality \\
\hline SL & 0.548 & 0.808 & 0.953 & 0.888 & 0.274 & 0.304 & 0.957 \\
\hline $\mathrm{TL}$ & 0.278 & 0.938 & 0.956 & 0.884 & 0.312 & 0.308 & 0.973 \\
\hline HL & 0.766 & 0.480 & 0.818 & 0.208 & 0.638 & 0.594 & 0.802 \\
\hline $\mathrm{BD}$ & 0.809 & 0.459 & 0.866 & 0.386 & 0.216 & 0.847 & 0.913 \\
\hline DL & 0.831 & 0.418 & 0.866 & 0.623 & 0.586 & 0.247 & 0.793 \\
\hline CL & 0.894 & 0.216 & 0.845 & 0.340 & 0.866 & 0.193 & 0.902 \\
\hline Eigenvalue & 4.687 & 0.617 & & 4.290 & 0.584 & 0.465 & \\
\hline$\%$ variance & 78.12 & 10.28 & & 71.51 & 9.74 & 7.75 & \\
\hline
\end{tabular}

PC: Principal component 1,2 and 3

The results of the principal component factor analysis applied to describe body conformation based on several unrelated components are presented in Table 3. Two principal components (factors) were extracted for Oreochromis niloticus while in Lates niloticus, three components were more informative. These principal components were determined from the six body measurements of the two fish species. PC1 in Oreochromis niloticus was characterized by head length, body depth, dorsal fin length and caudal fin length; while standard length and total length were associated with PC2. These two components together accounted for $88.4 \%$ of the total variation of the variables in the factor analysis. In the case of Lates niloticus, the first principal component had its loadings for standard length, total length and dorsal fin length, explaining $71.51 \%$ of the total variability. The second (characterized by head length and caudal fin length) and third component (primarily determined by body depth) together explained $17.49 \%$ of the generalized variance. The high communalities $(0.793-0.973)$ observed in the two fish species indicate that the variances of variables were efficiently reflected by the components. The present findings are congruous to the submission of Sangun et al. (2009) in Lizardfish.

Principal component factor score coefficients derived from the morphometric measurements of the two fish species are presented in Table 4. The use of multivariate techniques is receiving increased attention in stock management Sangun et al. (2009). The use of interdependent explanatory variables to predict body weight should be treated with caution, since multicollinearity has been shown to be associated with unstable estimates of regression coefficients (Keskin et al., 2007; Yakubu, 2009) rendering the estimation of unique effects of these predictors impossible. This justifies the use of factor scores for prediction. These factors are orthogonal to each other and are more reliable in weight estimation. Factor score values of the respective two and three factors of Oreochromis niloticus and Lates niloticus were used separately as explanatory variables in multiple linear regression model to predict body weight. 
Table 4. Factor scores for the prediction of body weight of fish

\begin{tabular}{lllllll}
\hline \multirow{2}{*}{ Trait } & \multicolumn{2}{l}{ Oreochromisniloticus } & & & Lates niloticus & \\
\cline { 2 - 3 } \cline { 6 - 7 } & PC1 & PC2 & & PC1 & PC2 & PC3 \\
\hline SL & 0.138 & 0.493 & & 0.626 & 0.272 & 0.124 \\
TL & 0.433 & 0.818 & & 0.599 & 0.221 & 0.138 \\
HL & 0.253 & 0.010 & & 0.432 & 0.413 & 0.504 \\
BD & 0.299 & 0.061 & & 0.156 & 0.412 & 1.084 \\
DL & 0.344 & 0.120 & & 0.214 & 0.329 & 0.264 \\
CL & 0.530 & 0.381 & 0.201 & 0.896 & 0.373 \\
\hline
\end{tabular}

PC: Principal component 1,2 and 3

It was observed that all the selected factors (independent variables) in both fish species had significant effect $(\mathrm{P}<0.001)$ on body weight. The Variance Inflation Factor (VIF) and the Tolerance values $(1.00$ in both cases) indicated that the problem of multicollinearity has been addressed (Table 5). A combination of the two independent factors in Oreochromis niloticus and the three orthogonal factors in Lates niloticus explained 76.6\% and $84.5 \%$ respectively of the total variability in the body weight of fish. The present observation on the prediction of body weight of fish from factor scores is consistent with the findings of Sangun et al. (2009). In a related study in birds, Yakubu et al. (2009) predicted slaughter weight of chickens using factor scores derived from the original body measurements.

Table 5. Multiple regression models for the prediction of body weight of fish

\begin{tabular}{|c|c|c|c|c|c|c|c|c|}
\hline Predictor & Constant & Coefficient & S.E. & t-value & Probability & $\mathrm{R}^{2}(\%)$ & VIF & $\mathrm{T}$ \\
\hline \multicolumn{9}{|c|}{ Oreochromis niloticus } \\
\hline PC1 & 6.139 & 0.145 & 0.007 & 21.072 & $<0.01$ & 76.6 & 1.00 & 1.00 \\
\hline $\mathrm{PC} 2$ & & 0.094 & 0.007 & 13.631 & $<0.01$ & & & \\
\hline \multicolumn{9}{|c|}{ Lates niloticus } \\
\hline $\mathrm{PC} 1$ & 6.442 & 0.119 & 0.008 & 15.673 & $<0.01$ & 84.5 & 1.00 & 1.00 \\
\hline PC2 & & 0.082 & 0.008 & 10.777 & $<0.01$ & & & \\
\hline $\mathrm{PC} 3$ & & 0.095 & 0.008 & 12.467 & $<0.01$ & & & \\
\hline
\end{tabular}

PC: Principal component 1,2 and 3

S.E. $=$ Standard error; $\mathrm{R}^{2}=$ Coefficient of determination; VIF $=$ Variance Inflation Factor; $\mathrm{T}=$ Tolerance

\section{Conclusion}

The use of factor scores in multiple regression models is advantageous because they eliminate the problem of multicollinearity, thereby facilitating the interpretation of the regression results. The information obtained in the present study could be useful in estimating growth rates, age structures and other components of fish population dynamics.

\section{References}

Alp, A., \& Kara, C. (2007). Distribution pattern and morphological differences between the sexes of river blenny, Salaria fluviatilis (Asso, 1801), in the Ceyhan river basin, Turkey. Turkish Journal of Zoology, 31, 113-120.

Cherif, M., Zarrad, R., Gharbi, H., Missaoui, H., \& Jarboui, O. (2008). Length-weight relationships for 11 fish species from the Gulf of Tunis (SW Mediterranean Sea, Tunisia). Pan-American Journal of Aquatic Sciences, 3, 1-5. 
Fafioye, O. O., \& Oluajo, O. A. (2005). Length-weight relationships of five fish species in Epe lagoon, Nigeria. African Journal of Biotechnology, 4, 749-751.

Ismen. (2002). A preliminary study on the population dynamics parameters of whiting (Merlangus merlangus euxinus) in the Turkish Black Sea coastal waters. Turkish Journal of Zoology, 26, 157-166.

Kalayci, F., Samsun, N., Bilgin, S., \& Samsun, O. (2007). Length-weight relationship of 10 fish species caught by bottom trawl and midwater trawl from the middle black sea, Turkey. Turkish Journal of Fisheries and Aquatic Sciences, 7, 33-36.

Keskin, S., Daskiran, I., \& Kor, A. (2007). Factor analysis scores in a multiple linear regression model for the prediction of carcass weight in Akkeci kids. Journal of Applied Animal Research, 31, 201-204. http://dx.doi.org/10.1080/09712119.2007.9706664

Mendes, B., Fonseca, P., \& Campos, A. (2004). Weight-length relationships for 46 fish species of the Portuguese west coast. Journal of Applied Ichthyology, 20, 355-361. http://dx.doi.org/10.1111/j.1439-0426.2004.00559.x

Omoniyi, I. T., \& Agbon, A. O. (2004). Morphometric variation in Sarotherodon melanotheron (Pisces: CICHLIDAE) from Brackish and Freshwater habitats in SouthWest Nigeria. Proc. of the $29^{\text {th }}$ Annual Conference of the Genetics Society of Nigeria, Oct. 11-14, 2004, University of Agriculture, Abeokuta, Nigeria. pp. 20-22.

Pinheiro, A., Teixeira, C. M., Rego, A. L., Marques, J. F., \& Cabral, H. N. (2005). Genetic and morphological variation of Solea lascaris (Risso, 1810) along the Portuguese coast. Fisheries Research, 73, 67-78. http://dx.doi.org/10.1016/j.fishres.2005.01.004

Sangun, L., Cankaya, S., Kayaalp, G. T., \& Akar, M. (2009). Use of factor analysis scores in multiple regression model for estimation of body weight from some body measurements in Lizard fish. Journal of Animal and Veterinary Advances, 8, 47-50.

SPSS. (2001). Statistical Package for Social Sciences. Version 13. SPSS Inc., 444 Michigan Avenue, Chicago, IL60611.

Tabachnick, B. G., \& Fidell, L. S. (2001). Principal components and factor analysis. In B. G. Tabachnick \& L. S. Fidell, Using multivariate statistics. (4th ed.). Needham Heights, MA, Allyn \& Bacon. pp. 582 - 633.

Truxillo, C. (2003). Multivariate Statistical Methods: Practical Research Applications Course Notes. SAS Version 9, Cary, NC: SAS Institute.

Wang, X. A., Ma, A. J., Xu, K., Lei, J. L., Yang, Z., \& Qu, J. B. (2008). Relationships between morphometric attributes and body weight of juvenile turbots Scophthalmus maximus. Acta Zoological Sinica, 54, 540-545.

Yakubu, A. (2009). Fixing collinearity instability in the estimation of body weight from morpho-biometrical traits of West African Dwarf goats. Trakia Journal of Sciences, 7, 61-66.

Yakubu, A., Idahor, K. O., \& Agade, Y. I. (2009). Using factor scores in multiple linear regression model for predicting the carcass weight of broiler chickens using body measurements. Revista Cientifica UDO Agricola, 9, 963-967. 